\title{
STUDY OF ELECTRICALLY ACTIVE DEFECTS IN EPITAXIAL LAYERS ON SILICON
}

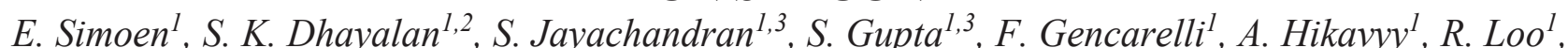

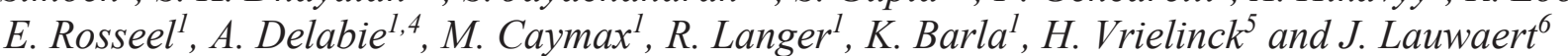

${ }^{1}$ Imec, Kapeldreef 75, B-3001 Leuven, Belgium

${ }^{2}$ Dept. of Physics, Celestijnenlaan 200D, B-3001 Heverlee, Belgium

${ }^{3}$ Dept. of Metallurgy and Materials, KU Leuven, Castle Arenberg 44, B-3001 Leuven, Belgium

${ }^{4}$ Dept. of Chemistry, KU Leuven, Belgium

${ }^{5}$ Dept. Solid State Sciences, Ghent University, Krijgslaan 281-S1, B-9000 Belgium

${ }^{6}$ Dept. of Electronics and Information Systems, Ghent University, St-Pietersnieuwstraat 41, Belgium

*Corresponding Author's Email: eddy.simoen@imec.be

\begin{abstract}
Electrically active defects in silicon-based epitaxial layers on silicon substrates have been studied by Deep-Level Transient Spectroscopy (DLTS). Several aspects have been investigated, like, the impact of the pre-epi cleaning conditions and the effect of a post-deposition anneal on the deep-level properties. It is shown that the pre-cleaning thermal budget has a strong influence on the defects at the substrate/epi layer interface. At the same time, a post-deposition Forming Gas Anneal can passivate to a large extent the active defect states. Finally, it is shown that application of a post-deposition anneal increases the out-diffusion of carbon from a $\mathrm{Si}: \mathrm{C}$ stressor layer into the p-type CZ substrate.
\end{abstract}

\section{INTRODUCTION}

A crucial step in silicon epitaxy is the preparation of a clean silicon surface prior to the deposition [1]. The removal of oxygen and carbon contamination is essential for a defect-free growth of good quality layers. However, besides the structural integrity of the epi layer, one should also be concerned with the presence of grown-in point defects, which may affect their electrical properties (resistivity, carrier lifetime,...). Previous Deep-Level Transient Spectroscopy (DLTS) studies have revealed several types of defects, which are usually ascribed to impurities present at the interface between the substrate and the epi layer [2]-[4]. Here, DLTS will be applied to address point-defect-related issues in silicon-based epi layers on silicon substrates.

\section{EXPERIMENTAL DETAILS}

Three sets of Chemical Vapor Deposition (CVD) epitaxial layers will be discussed, focusing on different aspects. In a first case study, the impact of the pre-epi clean procedure (ex situ HF dip in combination with in situ bake) will be explored, as there is a tendency to reduce the overall thermal budget during CVD. Here, the impact of the pre-epi bake temperature in the range of $750{ }^{\circ} \mathrm{C}-850{ }^{\circ} \mathrm{C}$ will be discussed. The effect of a post-deposition Forming
Gas Anneal (FGA) on the deep-level spectra is studied in a second case, where a standard $850{ }^{\circ} \mathrm{C}$ pre-epi bake of $\mathrm{p}-\mathrm{Si}$ is followed by a $500{ }^{\circ} \mathrm{C}$ deposition from $\mathrm{SiH}_{4}$. FGA is performed at $500{ }^{\circ} \mathrm{C}$ for $5 \mathrm{~min}$. A third set of samples focuses on blanket $\mathrm{Si}$ :C stressor layers on $\mathrm{p}$-Si substrates, in order to investigate the presence of interstitial carbon $\left(\mathrm{C}_{\mathrm{i}}\right)$ related deep levels in the underlying p-type Czochralski (CZ) Si substrate. As will be shown, the concentration of a $\mathrm{C}_{\mathrm{i}}$-related peak at $0.4 \mathrm{eV}$ above the valence band edge $E_{V}$ increases significantly after an 800 ${ }^{\circ} \mathrm{C}$ anneal, indicating that substitutional carbon is lost from the stressed $\mathrm{Si}$ :C layer by transforming into $\mathrm{C}_{\mathrm{i}}$ and related complexes, followed by diffusion into the $\mathrm{CZ}$ silicon substrate.

Processing details can be found, respectively in Refs. [4], [5] and [6]. Different device structures have been utilized to enable DLTS: either a p-n junction [4], a Metal-Oxide-Semiconductor (MOS) capacitor, based on $\mathrm{Al}_{2} \mathrm{O}_{3}$ gate dielectric or an $\mathrm{Al}$ Schottky barrier, evaporated on the Si:C epi layer.

\section{RESULTS AND DISCUSSION}

In order to evaluate the impact of different types of pre-epi cleaning on the epitaxial quality, $400 \mathrm{~nm} 1 \times 10^{17}$ $\mathrm{cm}^{-3} \mathrm{~B}$-doped Si layers have been deposited on n-type $\mathrm{CZ}$ Si substrates [4]. An ex situ HF clean was followed by a High Temperature Bake (HTB) in $\mathrm{H}_{2}$ for a temperature in the range 750 to $850{ }^{\circ} \mathrm{C}$. For one wafer, no pre-epi bake has been performed. As shown in Fig. 1, a broad distribution of electron traps can be observed at the interface/junction with the n-type substrate; their density-of-states is highest for the HF dip only (no bake) junction, based on the corresponding broader and higher peak. The origin is thought associated with residual impurities at the epitaxial interface, which become less effectively removed by the lower bake temperature [2]-[4]. At the same time, the corresponding junction leakage current increases significantly, for lower bake temperature, as demonstrated by Fig. 2 . It indicates that an 
increasing density of generation centers occurs in the depletion region and at the epitaxial interface.

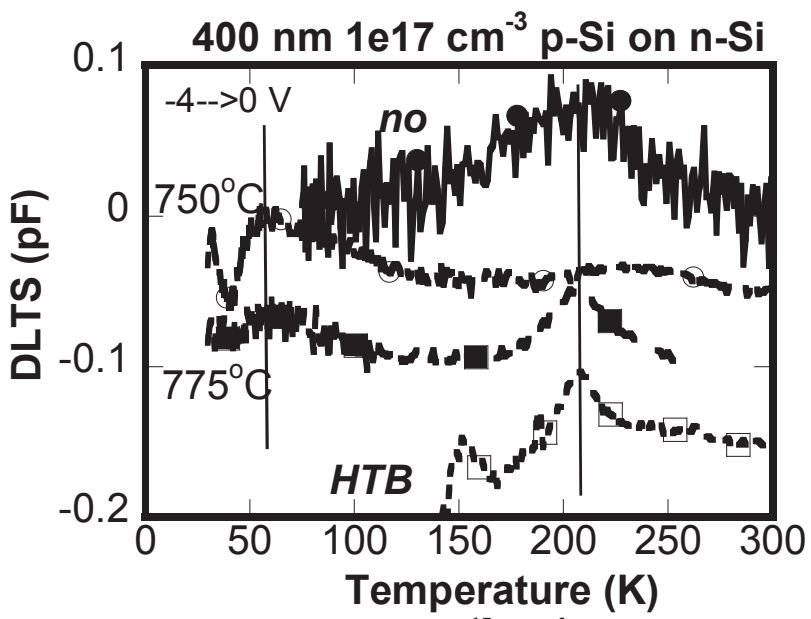

Figure 1: DLT-spectra of $1 \times 10^{17} \mathrm{~cm}^{-3} B$ doped Si epi layers on n-type silicon substrates, corresponding with different pre-epi bake temperatures. HTB: high-temperature bake at $1000{ }^{\circ} \mathrm{C}$. A bias pulse from $-4 \mathrm{~V}$ to $0 \mathrm{~V}$ has been applied. The spectra have been shifted in vertical direction for clarity.

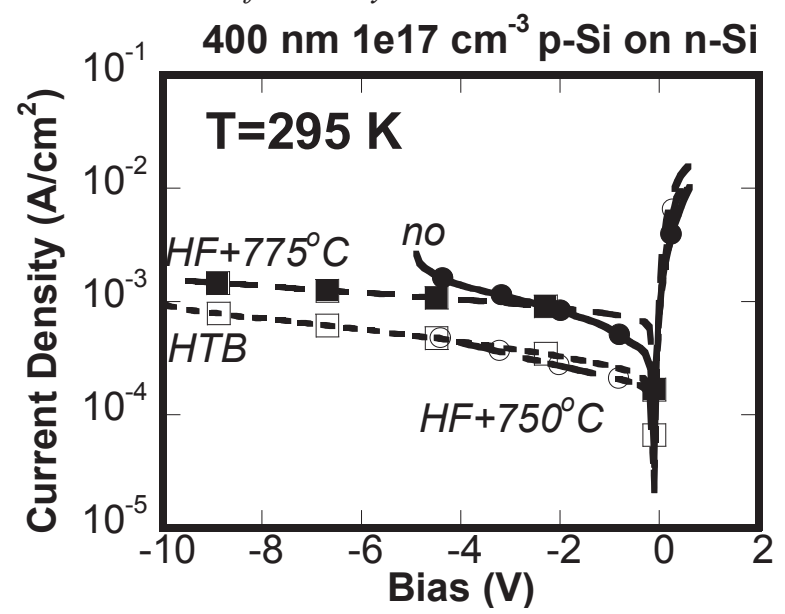

Figure 2: Current-Voltage characteristics at room temperature of $p^{+}-n$ junctions fabricated by $C V D$ deposition, using an ex situ HF clean, followed by a pre-epi bake at different temperatures.

It is clear that using a high-temperature pre-bake, gives rise to good-quality silicon epi layers. This is confirmed by the results of Figs 3 and 4, corresponding with $30 \mathrm{~nm}$ of silicon CVD at $500{ }^{\circ} \mathrm{C}$. The resulting epi layers, with p-type behavior based on the polarity of the MOS capacitor $\mathrm{C}-\mathrm{V}$ measurements, exhibit a low density of deep levels. According to the frequency scan of Fig. 3, a broad distribution of hole traps, present in the depletion region of the MOS capacitor, has been detected. The bias pulse conditions in Figs 3 and 4 are such that the DLT-spectra are dominated by hole traps in the depletion layer in the p-type silicon substrate + epi layer, suppressing the contribution from traps at the $\mathrm{Si}-\mathrm{SiO}_{2}$ interface. After a FGA at $500{ }^{\circ} \mathrm{C}$, most of the deep level defects present in the substrate/epi-layer have been passivated. This is confirmed by the flat temperature-scan spectrum in Fig. 4, corresponding with a bias pulse in depletion from $3 \mathrm{~V}-->2 \mathrm{~V}$.

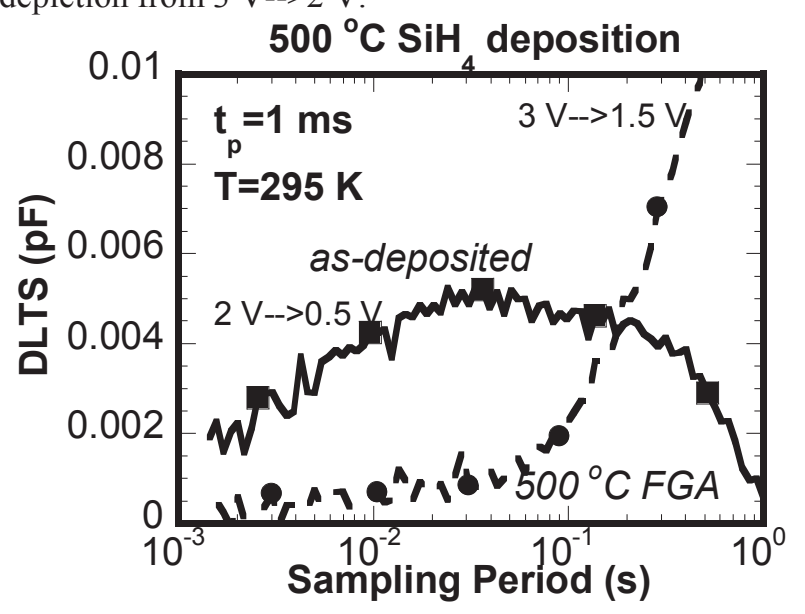

Figure 3: DLT-spectra at room temperature of low-temperature CVD p-type silicon on a p-Si substrate before and after a $500^{\circ} \mathrm{C} \mathrm{FGA}$ for $5 \mathrm{~min}$. A filling bias pulse of $1 \mathrm{~ms}$ has been applied.

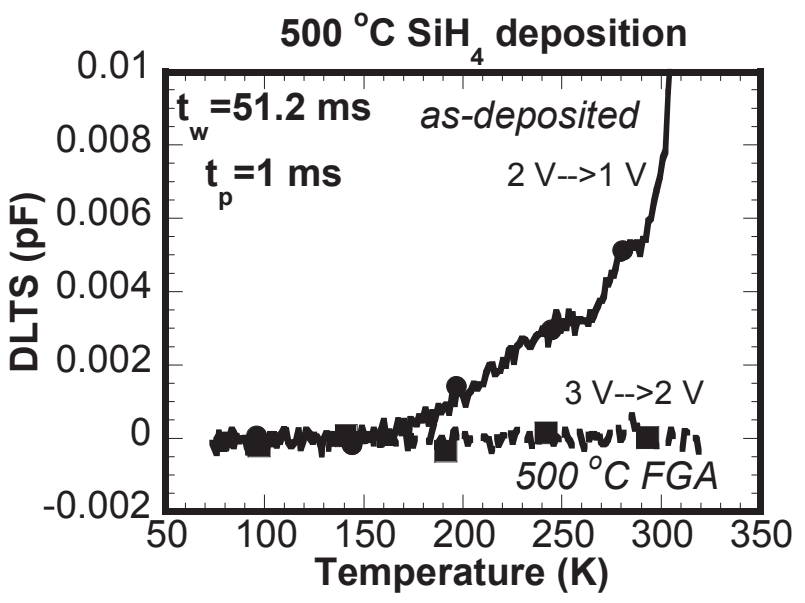

Figure 4: T-scan spectra of low-temperature CVD p-type silicon on a p-Si substrate before and after a $500{ }^{\circ} \mathrm{C} \mathrm{FGA}$ for $5 \mathrm{~min}$. A pulse period $t_{w}=51.2 \mathrm{~ms}$ and a filling pulse time $t_{p}=1 \mathrm{~ms}$ has been employed. The reverse bias of the measurements reflects the shift in flat band voltage of the capacitors upon annealing at $500^{\circ} \mathrm{C}$.

DLTS is also useful to investigate defects associated with the deposition of stressor layers, like, e.g., Si:C, which is useful for imparting tensile strain in n-channel Si bulk FinFETs [7]-[10]. In the case of undoped Si:C epi layers, the reverse bias pulse in DLTS probes mainly the p-type $\mathrm{Si}$ substrate for the presence of $\mathrm{C}_{\mathrm{i}}$-related species, diffused in from the $97 \mathrm{~nm}$ epi layer with a targeted 
substitutional $\mathrm{C}$ content of $1.6 \%$. Measurements have been performed after deposition and following annealing at 800 ${ }^{\circ} \mathrm{C}$ for 15 min under $\mathrm{N}_{2}$. Al Schottky barriers have been evaporated, enabling DLTS evaluation. For the as-grown material, a single hole trap with activation energy of 0.4 $\mathrm{eV}$ above the valence band edge is detected in Fig. 5, which most likely corresponds to the $\mathrm{C}_{\mathrm{i}} \mathrm{O}_{\mathrm{i}}$ peak in $\mathrm{CZ} \mathrm{Si}$ [11],[12]. The trap concentration increases roughly by a factor of 10 after $800{ }^{\circ} \mathrm{C}$ RTA in Fig. 6, indicating that more interstitial carbon species diffuse into the substrate. At the same time, it will be shown that larger C-related clusters give rise to a deeper band of hole traps closer to the epitaxial interface. This can partly explain the observed loss in strain of the stressor layer after annealing [6],[13].

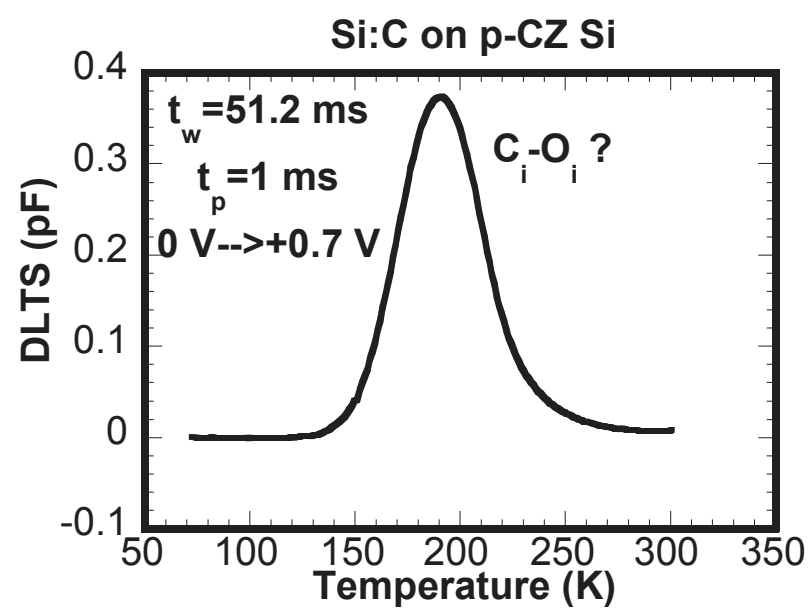

Figure 5: T-scan DLTS of an as-deposited Si:C epilayer on a p-type Si substrate at a bias pulse from $0 \mathrm{~V}$ to +0.7 $V$.

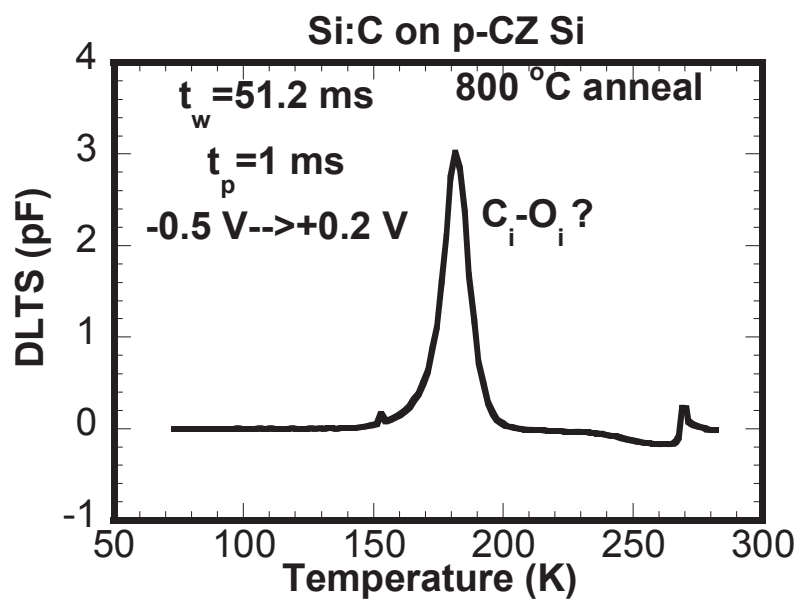

Figure 6: T-scan DLTS of an $800^{\circ} \mathrm{C}$ annealed Si:C epi layer on a p-type Si substrate at a bias pulse from $-0.5 \mathrm{~V}$ to $+0.2 \mathrm{~V}$.

\section{CONCLUSIONS}

In summary, it is clear that DLTS is useful in the study of electrically active point (and extended) defects in silicon epitaxial layers. A basic prerequisite, however, is the fabrication of proper device structures for addressing either the epi layer and/or the interface with the substrate.

\section{ACKNOWLEDGEMENTS}

This work has been performed in the frame of the imec Core Partner program. The epi layers were grown in Epsilon and Intrepid CVD systems from ASM.

\section{REFERENCES}

[1] R. Loo, a. Hikavyy, F. Leys, M. Wada, B. De Vos, A. Pacco, M. Bargallo Gonzalez, E. Simoen, P. Verheyen and M. Caymax, Solid State Phenom., pp. 177-180, 2009.

[2] D. Stievenard, X. Wallart and D. Mathiot, J. Appl. Phys., vol. 69, no. 11, pp. 7640-7644, 1991

[3] F. Lu, D. Gong, H. Sun and X. Wang, J. Appl. Phys., vol. 77, no. 1, pp. 213-217, 1995.

[4] E. Simoen, M. Bargallo Gonzalez, G. Eneman, E. Rosseel, A. Hikavyy, D. Kobayashi, R. Loo, M. Caymax and C. Claeys, ECS Trans., vol. 34, no. 1, pp. 761-768, 2011.

[5] S. Jayachandran, A. Delabie, J. Maggen, M. Caymax, R. Loo, J. Meersschaut, H. Lenka, W. Vandervorst and M. Heyns, Thin Solid Films, vol. 557, pp. 36-41, 2014.

[6] E. Rosseel, H.B. Profijt, A. Hikavyy, J. Tolle, S. Kubicek, G. Mannaert, C. L'abbé, K. Wostyn, N. Horiguchi, T. Clarysse, B. Parmentier, S. Dhayalan, H. Bender, J.W. Maes and S. Mehta, ECS Trans., vol. 64, no. 6, pp. 977-987, 2014.

[7] Q. Zhou, S.-M. Koh, T. Thanigaivelan, T. Henry and Y.-C. Yeo, IEEE Trans. Electron Devices, vol. 60, no. 4, pp. 1310-1317, 2013.

[8] Y.-T. Chuang, K.-H. Hu and W.-Y. Moon, J. Appl. Phys., vol. 116, no. 3, p. 033503, 2014.

[9] G. Mao, Y. Li and R. Yang, Proc. CSTIC '15, The IEEE (New York), pp. 1-3, 2015.

[10] M. Bauer, ECS Trans., vol. 50 (9), pp. 499-506, 2012.

[11] B.N. Mukashev, A.V. Spitsyn, N. Fukuoka and H. Saito, Jpn. J. Appl. Phys., vol. 21, no. 2, pp. 399-400, 1982.

[12] M.T. Asom, J.L. Benton, R. Sauer and L.C. Kimerling, Appl. Phys. Lett., vol. 51, no. 4, pp. 256-258, 1987.

[13] S. Dhalayan, J. Kujala, J. Slotte, G. Pourtois, E. Simoen, E. Rosseel, A. Hikavyy, Y. Shimura, S. Iacovo, A. Stesmans, R. Loo and W. Vandervorst, submitted to Appl. Phys. Lett. 